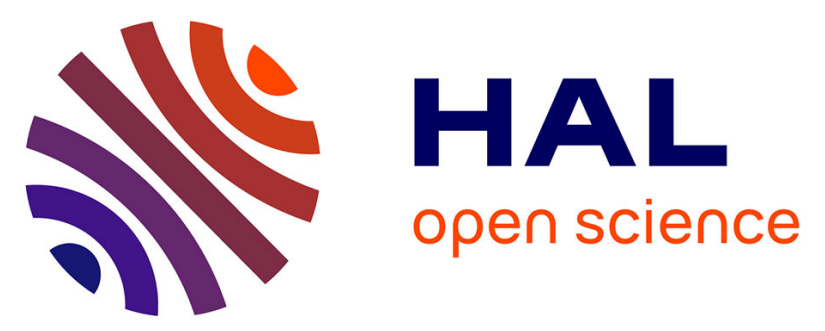

\title{
Structural integrity assessment of defected high density poly-ethylene pipe: Burst test and finite element analysis based on J-integral criterion
}

Mohamed Amine Guidara, Mohamed Ali Bouaziz, Christian Schmitt, Julien Capelle, Ezzedine Hadj Taieb, Zitouni Azari, Saïd Hariri

\section{To cite this version:}

Mohamed Amine Guidara, Mohamed Ali Bouaziz, Christian Schmitt, Julien Capelle, Ezzedine Hadj Taieb, et al.. Structural integrity assessment of defected high density poly-ethylene pipe: Burst test and finite element analysis based on J-integral criterion. Engineering Failure Analysis, 2015, 57, pp.282-295. 10.1016/j.engfailanal.2015.07.042 . hal-02972595

\section{HAL Id: hal-02972595 \\ https://hal.science/hal-02972595}

Submitted on 21 Oct 2020

HAL is a multi-disciplinary open access archive for the deposit and dissemination of scientific research documents, whether they are published or not. The documents may come from teaching and research institutions in France or abroad, or from public or private research centers.
L'archive ouverte pluridisciplinaire HAL, est destinée au dépôt et à la diffusion de documents scientifiques de niveau recherche, publiés ou non, émanant des établissements d'enseignement et de recherche français ou étrangers, des laboratoires publics ou privés. 


\title{
Structural integrity assessment of defected high density poly-ethylene pipe: burst
}

\section{test and finite element analysis based on $\mathbf{J}$-integral criterion}

\author{
M.A. GUIDARA ${ }^{1,2}$, M.A. BOUAZIZ ${ }^{1,2}$, C. SCHMITT ${ }^{2}$, J. CAPELLE ${ }^{2}$, E. HAJ TAIEB ${ }^{1}$ Z. AZARI $^{2}$, \\ S. HARIRI ${ }^{3}$ \\ ${ }^{1}$ Laboratoire de Mécanique des Fluides Appliqués, Génie des Procédés et Environnement, Ecole Nationale \\ d'Ingénieurs de Sfax, Université de Sfax, BP 1173, 3038, Sfax, Tunisie \\ ${ }^{2}$ Laboratoire de Biomécanique, Polymères et Structures (LaBPS), Ecole Nationale d'Ingénieurs de Metz, 57070 \\ Metz, France \\ ${ }^{3}$ Département Technologie des Polymères et Composites and Ingénierie Mécanique, Ecole des Mines de Douai, \\ 59508 Douai, France
}

\section{Abstract:}

The main objective of this study was to analyze the integrity of a defective high density polyethylene (HDPE) pipe by computing the J-integral. To this end, an experimental test was performed to measure the toughness and to determine the mechanical behavior of the HDPE. Many burst tests were achieved on longitudinally notched pipe specimens subjected to internal pressure. The defect was machined by a disc cutter with $0.5 \mathrm{~mm}$ thickness. So the notch geometry was given by the disc cutter penetration in the pipe wall. Numerical simulations based on the computation of the J-integral were used to analyze the fracture behavior of these structures (notched pipe and pre-cracked pipe). The numerical results were discussed and compared with the experimental tests. Using the critical value of J-integral, the numerical simulations allowed determining the crack initiation pressure and the opening stress in the vicinity of the defect root. Numerical results show that there is a gap between the crack initiation pressures of pre-cracked pipe and those of the notched pipe. This gap increases when the defect is deeper than half of the wall thickness. These pressures decrease parabolically with the defect depth.

Keywords: HDPE pipe, J-integral, Notch, Burst test, J-R curve 
Nomenclature

\begin{tabular}{|ll|}
\hline$a$ & defect depth \\
$a_{0}$ & Original crack length \\
$d$ & Defect length \\
$d_{e}$ & Opening displacement \\
$p$ & Outside diameter of the disc cutter \\
$t$ & Internal pressure of the pipe \\
$u$ & Wall thickness \\
$D_{e}$ & Displacement \\
$J$ & Outside diameter of pipe \\
$J_{I c}$ & J-integral \\
$U$ & J-integral critical value \\
$U_{i}$ & Energy \\
$U_{T}$ & Indentation energy \\
$\dot{\varepsilon}$ & Total energy \\
$\eta$ & Strain rate \\
$\sigma_{\theta \theta}$ & Geometric factor \\
$\Delta a$ & Circumferential stress \\
\hline
\end{tabular}

\section{Highlights}

- J-R Curves and toughness $J_{I C}$ of HDPE PE100 have been obtained experimentally.

- Burst tests were achieved on longitudinally notched PE 100 pipes.

- 3D-FEM model based on J-integral criterion was used to analyze the defect severity.

- Both longitudinal notch and crack were numerically studied and compared.

- The numerical results show a good agreement with the experimental burst pressures. 


\section{Introduction}

According to the Freedonia Group specialized in industry market research and analysis[1], "Plastic pipes will offer the best growth of any product type through 2017.Global demand for plastic pipes is projected to rise 8.5 percent annually through 2017 to 11.2 billion meters, improving significantly from growth posted between 2007 and 2012.High density polyethylene (HDPE) pipes, which have historically been used largely in the oil and gas market, will continue to make gains in the water pipe market. PEX, a type of HDPE, can replace Polyvinyl chloride (PVC) and metal pipes in distribution applications. HDPE pipes will also supplant concrete, PVC, and steel pipes in drainage and storm sewer applications". The HDPE is the chosen material for fluid transport network pipelines thanks to its good resistance to wear and corrosion, low density, ease of installation and low cost. However compared to ductile iron and concrete pipes, the HDPE is a very soft material and consequently more vulnerable to abrasions, scratches, and other damage types during shipping and installation. In fact, ANSI/AWWA C906[2]states that "the walls shall be free from cuts, cracks, holes, blisters, voids, foreign inclusions, or other defects that are visible to the naked eye and that may affect the wall integrity." This is an arguably impractical stipulation relative to many rugged construction sites.

The accurate prediction of the failure pressure in damaged pipelines remains a critical issue for the safety assessment of high-pressure piping systems. Defect assessment in a pipeline is achieved using different tools according to the defect types and fracture modes.

Several authors [3-12] have studied pipe fracture problems by means of experimentation and numerical simulation in order to assess the mechanical integrity, taking into account different crack shapes.

Unfortunately, there are only a few scientific publications dealing with the failure of the polymer pipes. Benhamena et al. [13, 14] analyze the severity of semi-elliptical crack defects located in different positions in the wall of a poly-ethylene pipe using the three finite element method based on the computation of the J-integral. The effect of the position, shape, and size of the crack on the J-integral was highlighted. These studies, however, were limited to crack defects and without any experimental validation.

Since HDPE is a viscoelastic material, Linear elastic fracture mechanics (LEFM) theory cannot be applied and the total work of fracture must include the various forms of plastic deformation, which appear prior to and during any failure 
The problems associated with the LEFM analysis on polymers have led to the development of several elastic-plastic fracture analyses, with both of the J-integral and the Essential Work of Fracture (EWF) as the most commonly used approaches. The EWF concept is very useful in the characterization of the fracture behavior of films and sheets. Experimental protocols were developed by the European group ESIS (European Structural Integrity Society) for measuring the Essential Work of Fracture in plane stress state. The authors in [15-16] have tried to operate this method in the plane strain state but it has not been normalized yet.

For a ductile material, the gradual increase of plastic strain at the crack tip during initiation and propagation causes an increase and a stabilization of its cracking resistance. The crack extension resistance becomes a function of the specimen's size and geometry. So, the toughness of the material cannot be represented by a single critical parameter $\left(K_{c}\right.$ or $\left.G_{c}\right)$ but by the R-curve $(J=f(\Delta a))$. This curve describes the energy conditions required by an additional crack extension after the crack initiation. It indicates at the same time when and how the rupture will occur.

The J-integral, developed by Rice [17], is defined as a contour integral, which describes the energy per unit area needed for the creation of two new surfaces in a cracked body submitted to loading. When the J-integral reaches the critical value $\left(J_{I c}\right)$ the crack propagates. $J_{I c}$ can be considered as a material parameter.

In the present works, longitudinally defective PE100 pipe specimens subjected to internal pressure were numerically studied. A series of full scale burst tests were performed on the same closed-end pipe specimens. Experimental and numerical results were compared and analyzed.

In the first part of the paper, we recall the Elastic-Plastic Fracture Mechanics theory (EPFM) based on the J-integral concept. Laboratory testing of the PE100 material was performed at room temperature. Deep crack "CT" specimens provide the needed data to measure the crack growth resistance curve J- $\Delta \mathrm{a}$ (R-curves) of the material. In the second part, 3D-FEM based on the computation of the J-integral [17] at both notch and crack front was used to analyze the defect severity. This led to study the evolution of damage degree in the equipment (HDPE pipe) under internal pressure during its propagation. Finally, experimental burst tests were performed on PE100 vessels containing a longitudinal notch defect.

The remaining of this paper was organized as follows: section two described the experimental procedure. Section three was devoted to numerical simulations. In section four, the numerical and experimental results were analyzed and discussed before drawing the major conclusion in section five. 


\section{Experimental section}

\subsection{Mechanical behaviour of the material}

High Density Polyethylene (HDPE) is a thermoplastic material supplied by the manufacturer in a 'ready to use' pelletized form. The grades suitable for pipe manufacture are PE 63, PE 80 and PE100. The pipe manufacturer converts this material into pressure pipes.

For drinking water application HDPE strength class PE100 is widely used. These materials are termed as "the third generation HDPE". The evolution of the true axial stress versus axial strain for different strain rates of PE100 was investigated by Ferhoum [18]. The test specimens were cut from the HDPE pipe in the axial direction. Images supplied by a camera of VideoTraction system were used. The results of this investigation were used in our study to characterize the material on ABAQUS. However, one of the main drawback of the VideoTraction system is the low precision in the characterization of the viscoelastic region. Indeed, in the beginning of deformation, the specimen cross section does not change significantly and the accuracy of the data acquisition system (typically of the order of $+/$ $30 \mu \mathrm{m}$ ) in ordinary conditions of use, does not allow obtaining reliable measures [19]. For these reasons, tensile tests were conducted on a standard traction-compression machine piloted in a displacement mode using an extensometer in order to better characterize the material at low deformations. This allows us to accurately determine the elasticity modulus, Poisson's ratio of PE100 and the viscoelastic region. These tests were carried out at three different test strain rates. A stress-strain curve for each strain rate is represented in figure1.

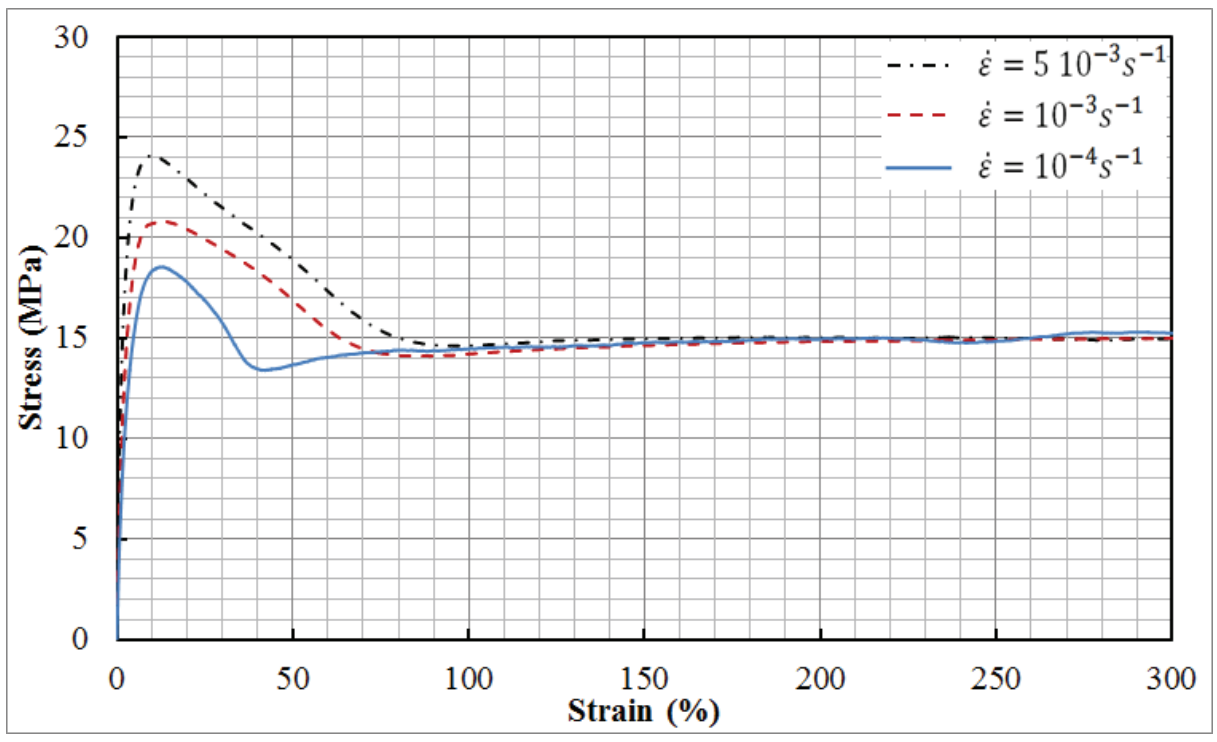

Figure 1.Stress-strain curves for the HDPE 


\subsection{The J-Integral}

To define the J-integral as a fracture criterion, extensive experimental investigations on the Jintegral testing were conducted in order to evaluate the critical value $\left(J_{I c}\right)$ for the onset of a crack growth under plane strain conditions.

Several methods (ASTM D6068) [20] have been developed specifically to determine the crack growth resistance curves (J R-Curves) of thermoplastic polymeric materials. The construction method involves performing standard compact tension (CT) tests to different displacements with the same speed $(10 \mathrm{~mm} / \mathrm{min})$ recommended by The ISO 13586 standard [21]. CT specimens (figure 2), used for the tensile test, were machined by abrasive water jet cutting. A razor blade was used across the root of the machined pre-notch to generate the crack.

Load-line displacement measurements for each imposed openness (figure 3), are used to calculate the J-integral from the area under the recorded load-displacement which is the Total Energy "UT". The remote displacement measurement is performed using the position transducer on the testing machine. The obtained data were corrected for extraneous displacements (such as indentation effects, pin penetration, or machine compliance) by conducting a separate indentation measurement. The Low gap observed in Figure 3 between load displacement curves is due to low accuracy of the pre-crack. An unnotched calibration specimen that is of the same geometry as the individual specimens used in the $\mathrm{J}$ tests has been used for the indentation correction [20].It has been loaded to a maximum load that is at least $10 \%$ greater than the maximum load used in the set of individual $\mathrm{J}$ tests (figure $4 \mathrm{~b}$ ). The loading rate and test temperature are the same for the indentation correction and $\mathrm{J}$ tests.

The indentation energy, "Ui", for each J test specimen is obtained by integrating the load versus load-point displacement curve measured in the indentation test up to the displacement that corresponds to the maximum load $(\mathrm{F}(\max ))$ for that $J$ test specimen (figure 4).

Using $U_{T}$ and $U_{i}$, the $\mathrm{J}$ can be calculated for all the tested specimens by the relationship

$$
J=\frac{\eta\left(U_{T}-U_{i}\right)}{b\left(W-a_{0}\right)}
$$

where $\eta$ is a dimensionless eta factor that depends solely on geometrical parameters but not on the level of deformation [22]. Garcia et al [23] affirms that for J-testing of polymers, eta factor is functions of crack length to width ratio (a/W). Clarke and Landes [24] obtained an approximate fitted function of the $\eta$ factor for compact tension specimens as: 


$$
\eta=2+0.522\left(1-\frac{a_{0}}{W}\right)
$$

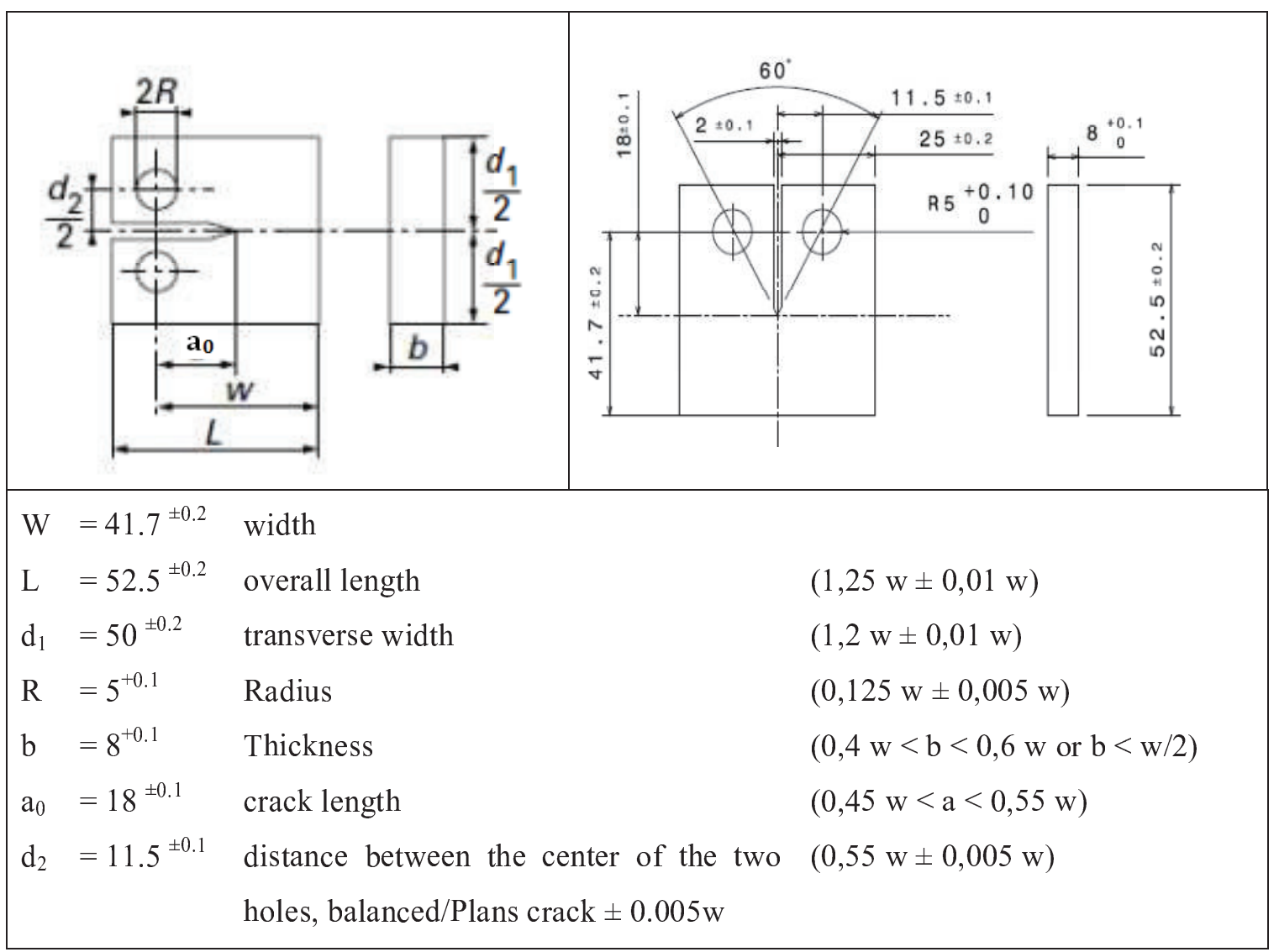

Figure 2.Standard compact tension (CT)

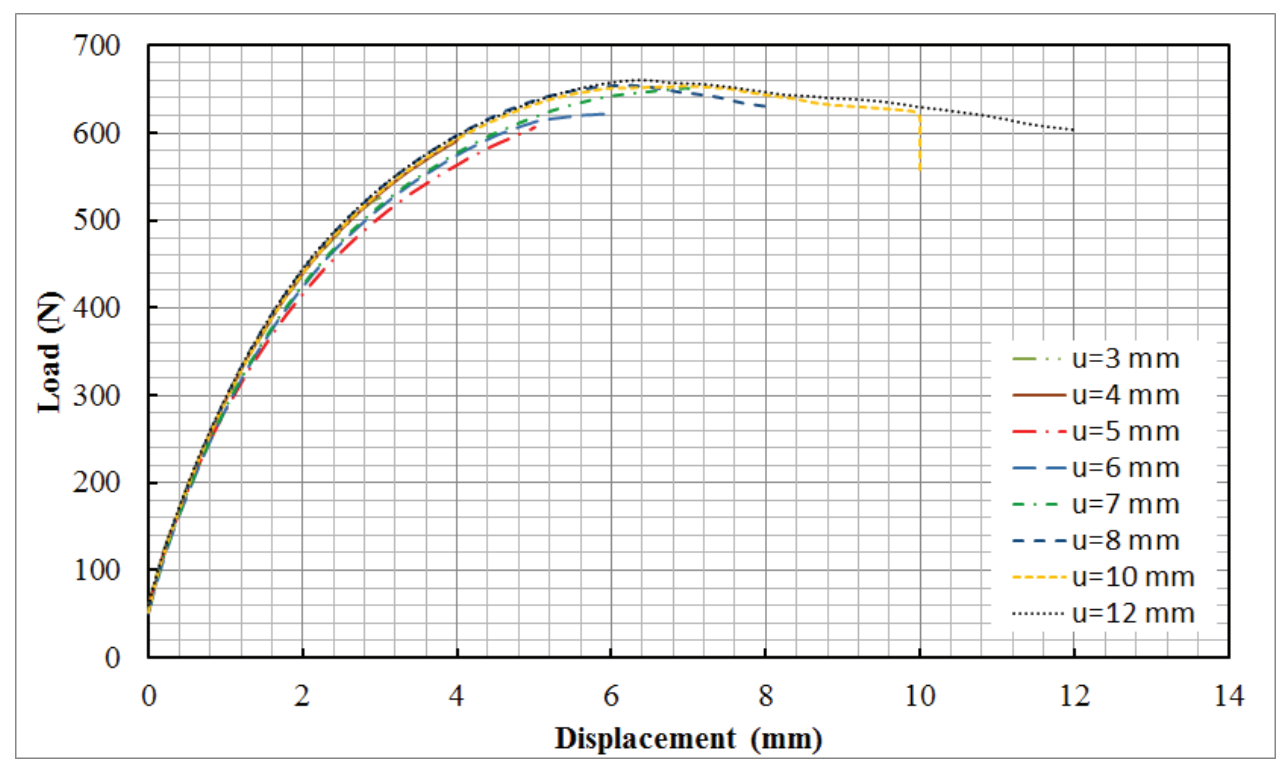

Figure 3. Load-displacement curve 


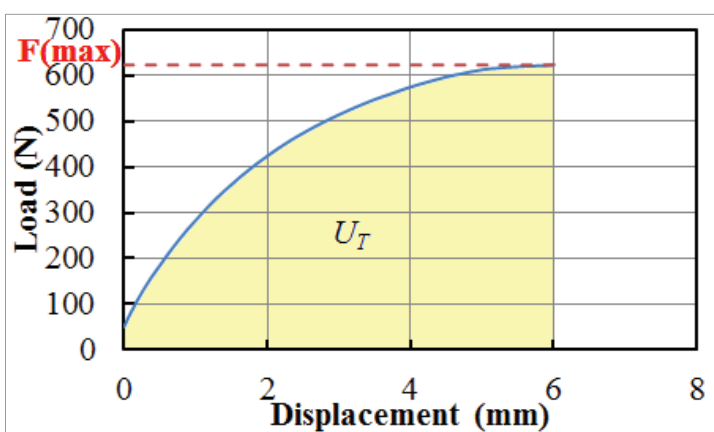

a) Notched specimen $(\mathrm{u}=6 \mathrm{~mm})$

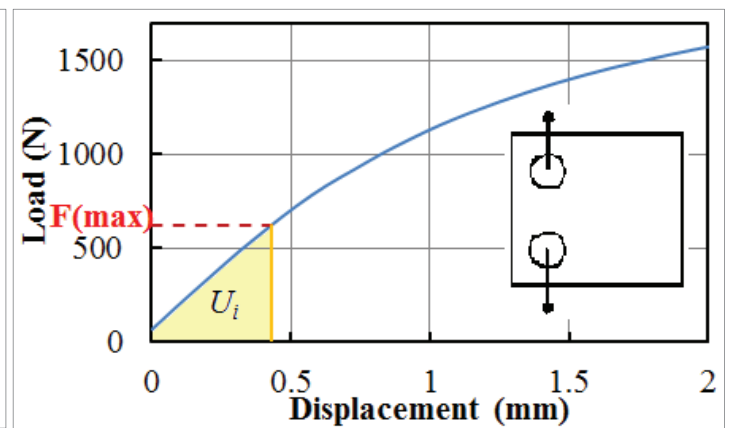

b) Unnotched specimen

Figure 4.Determination of the total and the indentation energy

When the traction machine reaches the imposed displacement, a white paint is applied to mark the different areas of the fracture surface. This surface is observed by a3D Optical microscope and shows the characteristic dimple-type of a ductile tearing mode (Figure 5).

The original crack length, $a_{0}$, is calculated from the average of three measurements from one side of the specimen along the original crack front on the fracture surface. Along the front stable crack extension region, the crack length was measured at five equally spaced points (Figure 5). The average physical crack extension $\Delta a$ is calculated from these measurement points.

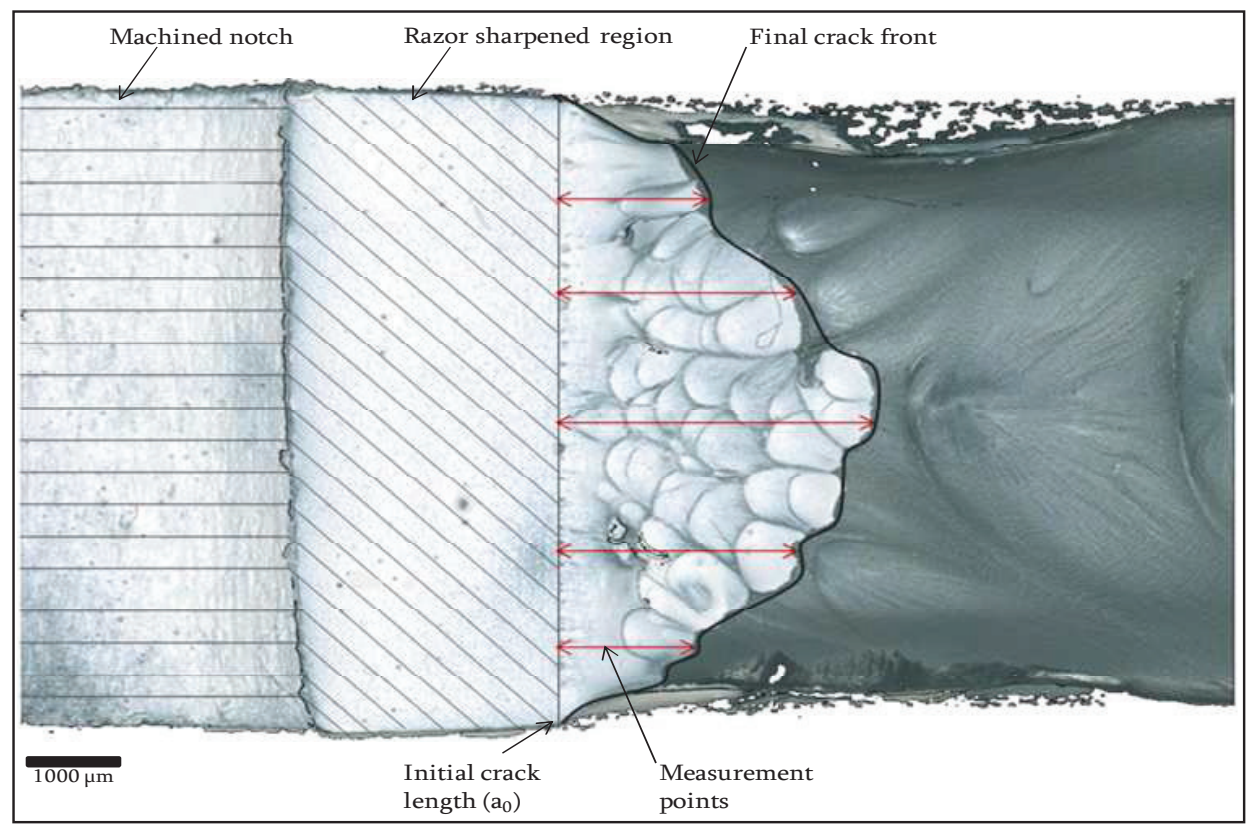

Figure 5.Measurement of crack-extension ( $\Delta a)$

The J-R curve is constructed from J- $\Delta$ a sets of the data determined as previously described. Figure 6 shows a representative crack growth resistance curve (J-R curve) obtained from an 8 $\mathrm{mm}$ thick CT specimen by the above described procedure. 
For the determination of the toughness in $J_{I c}$, besides the method of the offset construction line recommended by the ASTM E 813 [25], some authors choose to alternately define $J_{I c}$, for polymeric materials, as the value of J-integral for a crack extension set at 0.2 or $0.4 \mathrm{~mm}$ [2628]. So $J_{0,2}$ corresponding to the value of the J-integral for $\Delta a=0.2 \mathrm{~mm}$ can be considered as a critical value which characterizes the crack initiation [26]. This assumption was discussed in sub-section 3.2 .

In the case of HDPE, figure 6 shows that the critical fracture toughness $\left(J_{I c}\right)$ is equal to $7.69 \mathrm{~kJ} / \mathrm{m}^{2}$.This value is quite logical because fracture toughness for HDPE determined using the same approaches showed significant variations, from as low as $7 \mathrm{~kJ} / \mathrm{m}^{2}$ to above $20 \mathrm{~kJ} / \mathrm{m}^{2}$ [29].

This value was inserted in the ABAQUS software to determine the internal pressure which leads to the crack initiation in the pipe.

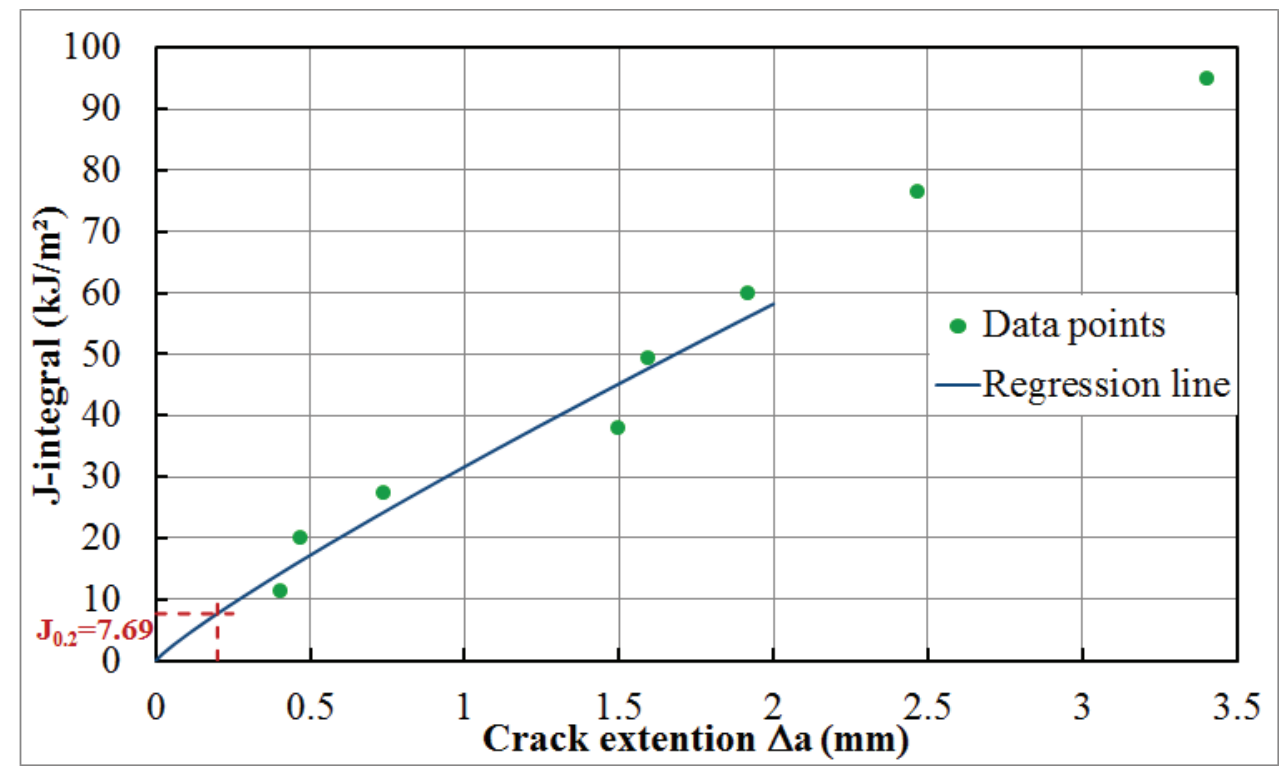

Figure 6.Crack growth resistance curve (R-Curve)

\subsection{Burst tests}

\subsubsection{Pipe specimen geometry}

The experimental study was made on PE100 pipe specimens. The dimensions of the pipe pieces, shown in figure 7, are $400 \mathrm{~mm}$ length, of thickness $t=12 \mathrm{~mm}$ and external diameter $D_{e}=125 \mathrm{~mm}$ with different external notches. 
Notches are machined by a disc cutter that has a plate thickness of $0.5 \mathrm{~mm}$ and an outer diameter $\left(d_{e}\right)$ of $80 \mathrm{~mm}$. The depth of the notch $(a)$ is due to the disc cutter penetration depth into the pipe wall. Figure 7 shows the geometries of the defected test specimen.

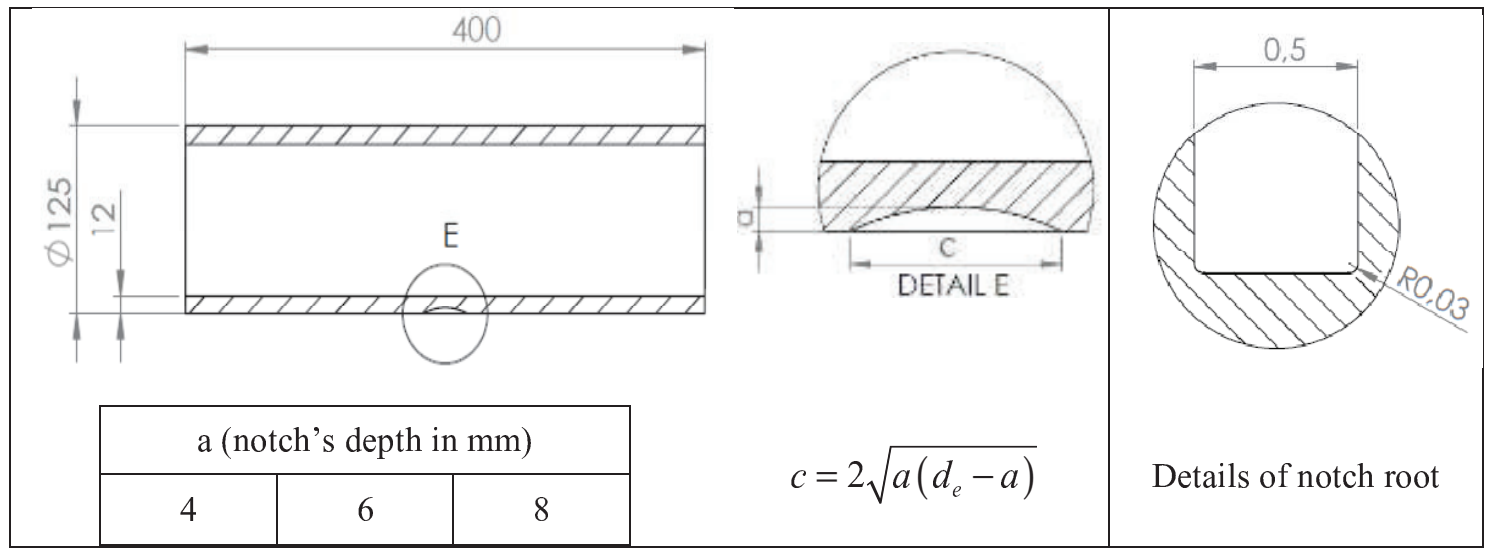

Figure 7.Notched pipe geometry

\subsubsection{Test process and results}

To validate the theoretical method, burst tests were conducted under various temperatures. The structural parameters of the PE 100 specimen are listed in figure 8. All specimens were made from the same material and production batch. Test temperature was set at $20{ }^{\circ} \mathrm{C}$, and three specimens were used for each group of tests.

Figure 8 shows the details of the clamp, with a flange 3 and chucking parts 2 and 7 forming the main structure of the clamp by the clumping nut 8.Closed-end PE100 specimens were exposed to internal pressure tests using the testing apparatus shown in figure9(b).

The outer surface of the compressing part 6 bears a tooth system that runs in the hoop direction. The compressing part 6 is pressed on the inner surface of PE100 1 such that the loads exerted on compressing part 6, particularly those in the axial direction, can be transmitted reliably to the PE100 to limit the axial displacement of the pipe. A compressing part 5 is next to the compressing part 6 . Compressing part 5 is pressed against a gasket 4 , which efficiently prevents water leakage. The assembled cap has a size of $100 \mathrm{~mm}$. 


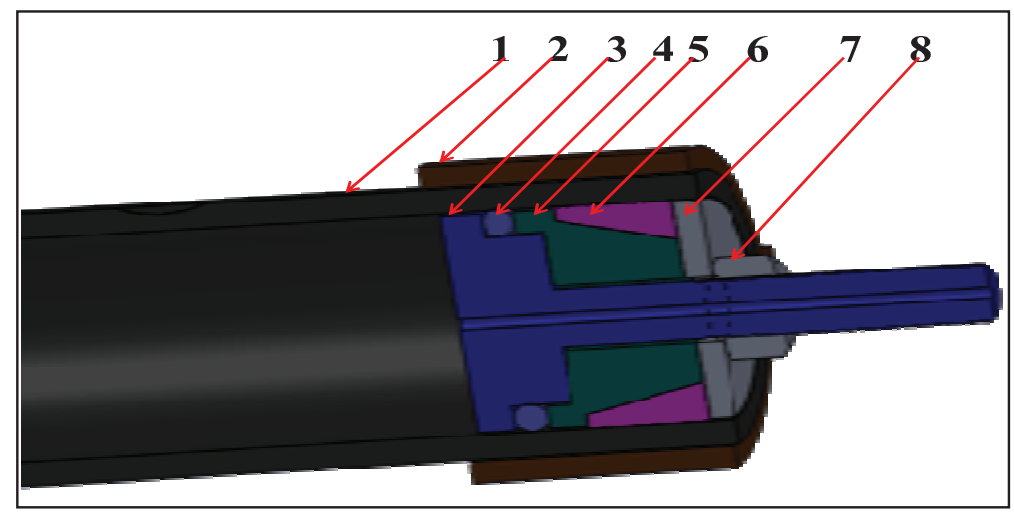

Figure 8.Details of the test apparatus; 1: PE100; 2: chucking; 3: flange;4: gasket; 5 , 6: compressing parts; 7: chucking; 8: clamping nut

A controlled burst test machine was used, and the pressure controlling precision reached up to $0.01 \mathrm{MPa}$. Closed end specimens were initially filled with water at atmospheric pressure than they have been loaded by forcing water in with a continuous pressure rate of 12 bar per minute until failure (figures 9).

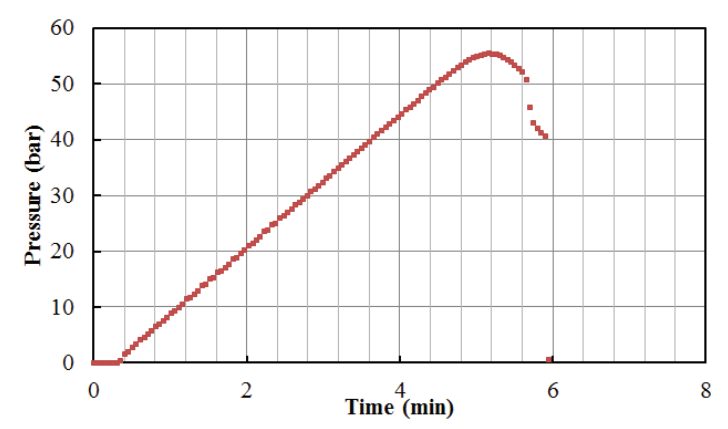

(a)

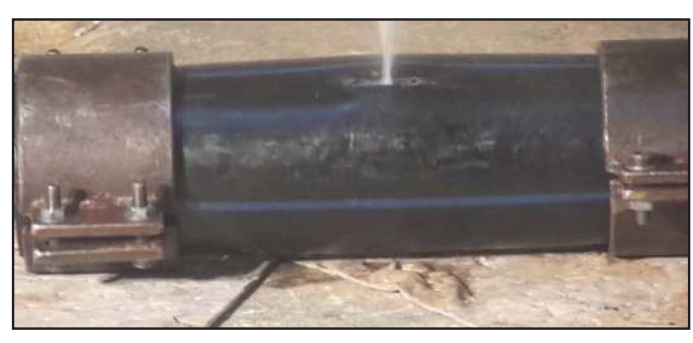

(b)

Figure 9.Typical specimen failure of short-term burst tests

The measurement results are presented as a curve of pressure versus volume of added water until failure (figure 10).Although these curves have the same shape which is quite independent from the notch depth, the burst pressures are greatly affected by such a depth. Table 1 shows the effect of the notch depth on the burst pressure. 


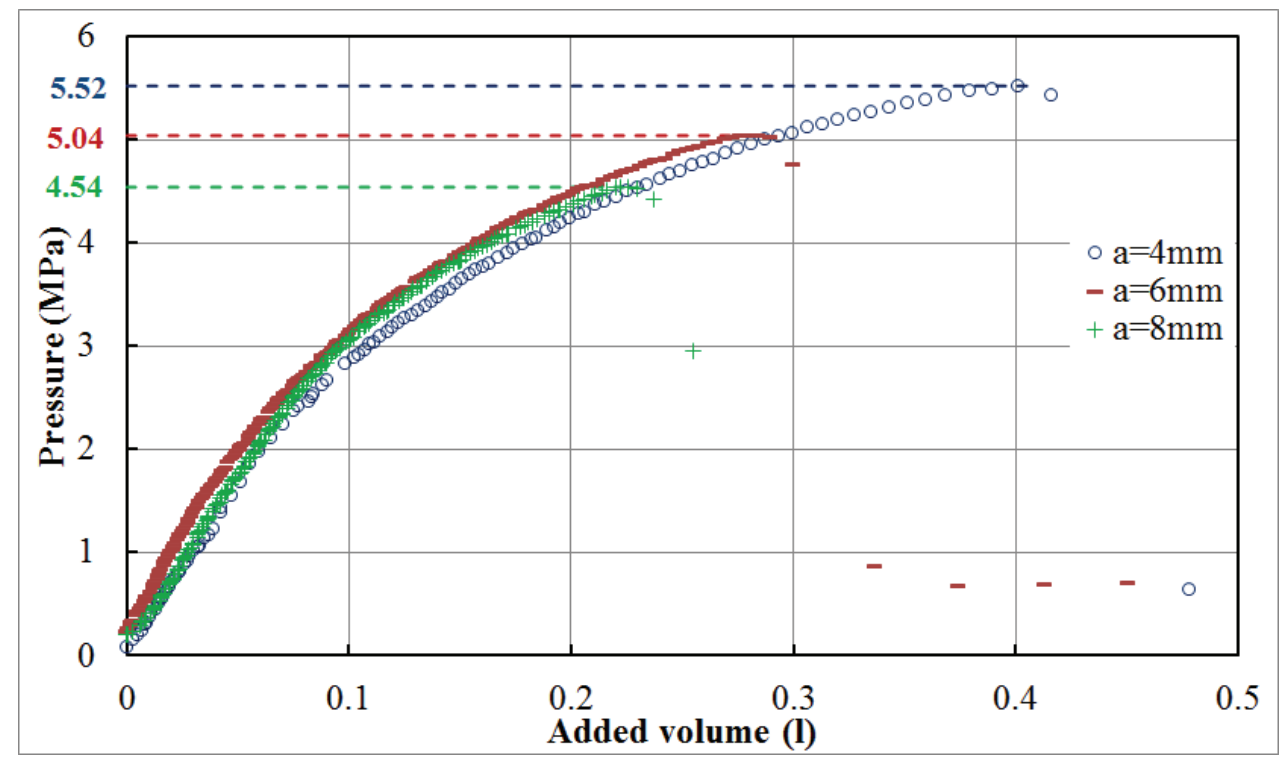

Figure10.Internal pressure vs added volume (Burst test) $(a=$ Notch depth

Table 1.Burst pressure for each pipe specimens

\begin{tabular}{|l|c|c|c|}
\hline Notch depth (mm) & 4 & 6 & 8 \\
\hline Burst pressure (MPa) & 5.52 & 5.04 & 4.54 \\
\hline
\end{tabular}

In addition to the experimental study, the defective PE100 pipe subjected to internal pressure were numerically simulated by the means of FEM model based on the J-integral criterion. The experimental and numerical results were compared

\section{Numerical Modelling}

The crack behavior was analyzed by computing the J-integral at the crack front of a longitudinally pre-cracked pipe and a notched pipe. It is necessary to study and analyze the difference between pre-crack and notch. Five defect depths were considered in order to determine the effect of the depth on the pressure leading to the crack initiation in the polyethylene pipe.

\subsection{Finite element modelling}

A finite element simulation was performed using the ABAQUS (FEA). The numerical simulation of three dimensions crack propagation is known to be tricky for reasons related to the mesh near the notch front, especially when it comes to polymer materials.

Figures 11, 12 and 13 show a three dimensional representations (3-D FE) of the finite element mesh. Assembled burst tests specimens (pipe +cap) were modeled as a rigid body by a $20 \mathrm{~mm}$ closed ends pipe (Figure 11-a).Symmetric conditions were fully used. Only a quarter of the 
model was studied in order to reduce the computation time. The specimen was loaded with an internal pressure $\mathrm{P}$ uniformly distributed over the entire inner surface of the model (pipe + cap) with a continuous pressure rate of $12 \mathrm{bar} / \mathrm{min}$ (Figure 11-b).

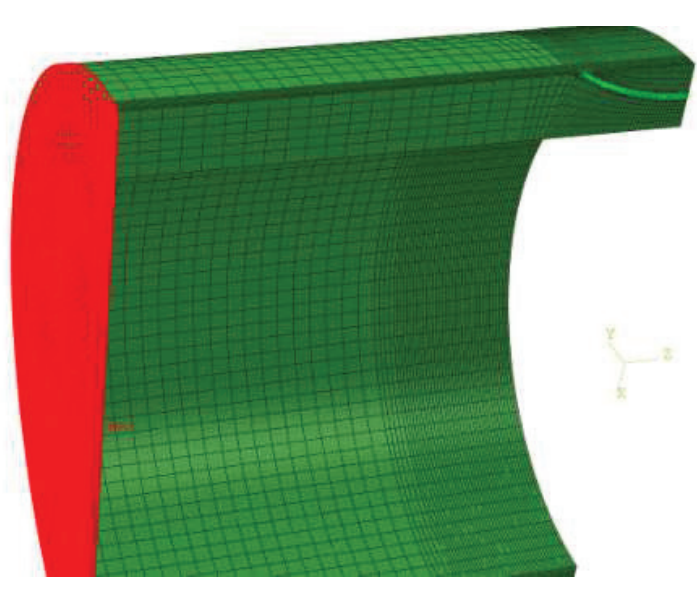

a) Cap was defined as rigid body elements.

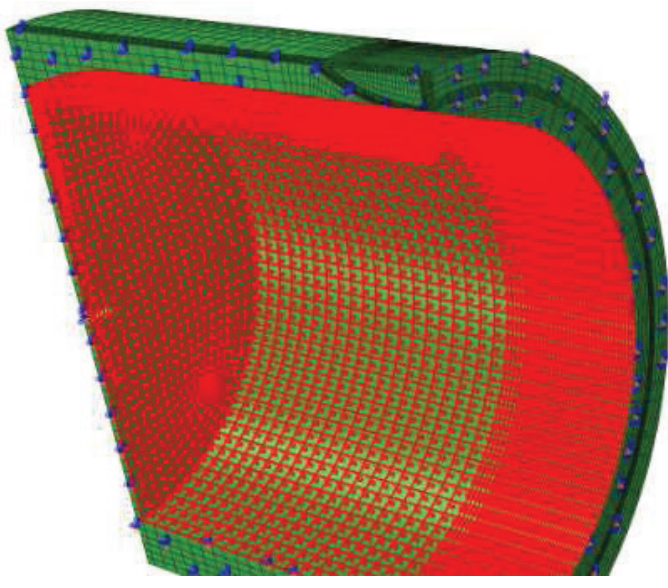

b) Load and Boundary conditions

Figure11.3D pipe Mesh

The quarter of the specimens were meshed by HyperMesh using C3D20 which is a second order element consisting of 20 nodes. Several contour integral evaluations are possible at each location along the crack front. In a finite element model each evaluation can be thought of as the virtual motion of a block of material surrounding the crack tip. Each such block is defined by contours: each contour is a ring of elements completely surrounding the crack tip or crack front from one crack face to the opposite crack face.

The mesh was sufficiently refined in the vicinity of the crack tip with special elements to increase the accuracy in local area and predict the J-integral correctly. Seven ring elements surrounding the crack tip were used to evaluate the contour integrals. These rings of elements are defined recursively to surround all previous contours. The first contour was the crack tip caused by disc cutter penetration into the pipe wall (Figures7 and 12). This is defined in ABAQUS/CAE as the crack front. After that the virtual crack extension direction was defined by specifying the normal to the crack plane as shown in figures 12 and 13 .

Generally, the nodes number in typical FE meshes ranges between 200000 and 320000 nodes. To include the nonlinear effects of large displacements, the NLGEOM_ABAQUS option was used.

As HDPE is a high strain rate sensitive material, the FE model takes into account the variation of the strain rate by using the strain-stress curves at different strains rate $\left(510^{-3}, 10^{-3}\right.$ and $\left.10^{-4}\right)$ explained in subsection 2.1. 


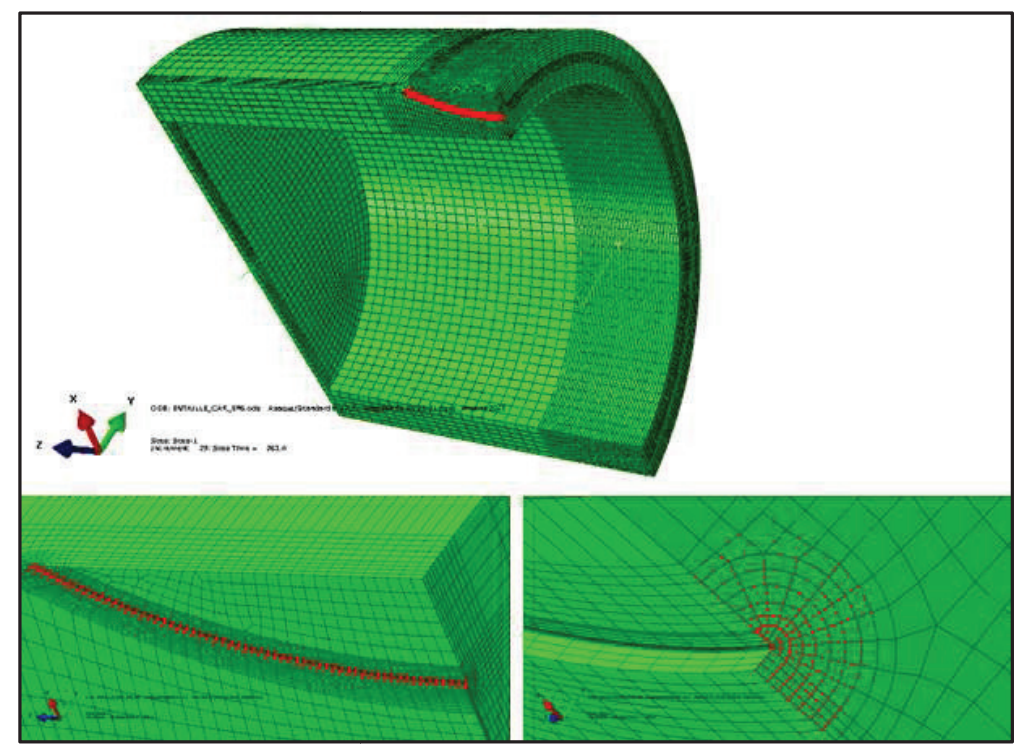

Figure12.3D Notched pipe Mesh

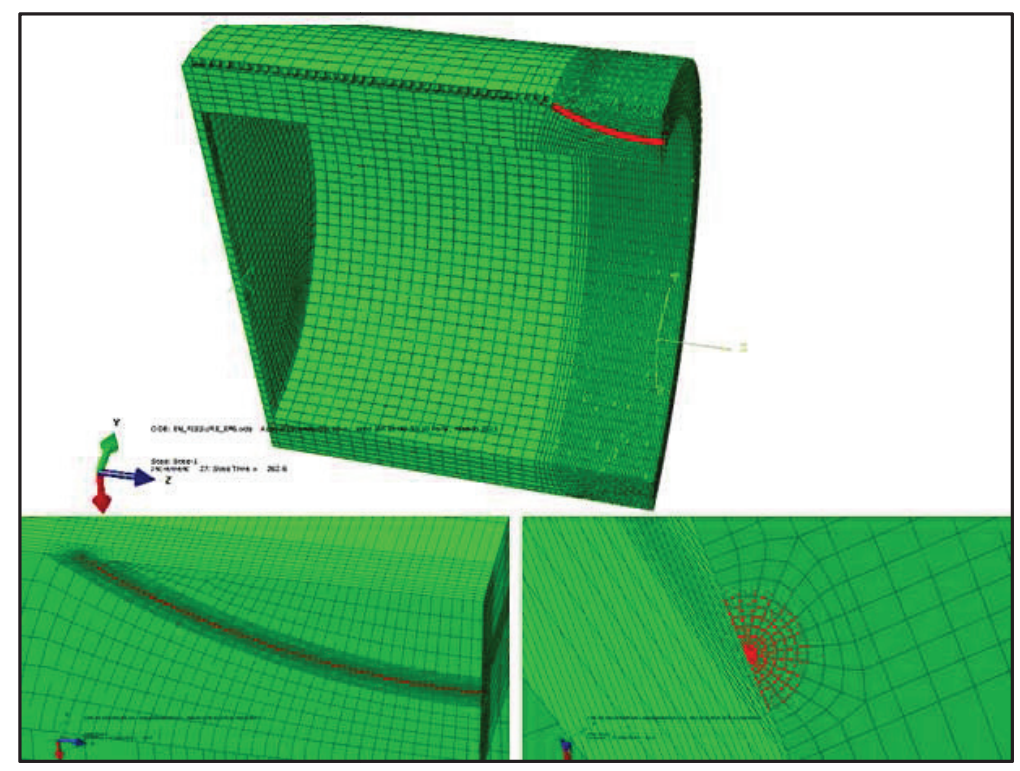

Figure13.3D Pre-cracked pipe Mesh

Thermoplastic materials such as PE 100 have a viscoelastic behavior and a high degree of ductility. For this kind of materials, the viscoelastic-plastic fracture mechanics concept is recommended to analyze the fracture behavior (the initiation and propagation of cracks) [30, 31]. Benhamena et al. [13, 14], however, showed that elastic-plastic approaches can approximate the critical J-integral of the polyethylene with acceptable accuracy. 


\subsection{Results and discussion}

The values of $\mathbf{J}$ integral depend on the current point of the crack front characterized by the angle $\theta$ (from $\theta=0^{\circ}$ to $\theta=90^{\circ}$, see figure 14). The analysis was limited to one particular point in the crack front characterized by the angle $\theta=90^{\circ}$ (position 1). It is the point where the J integral presents the maximum values.

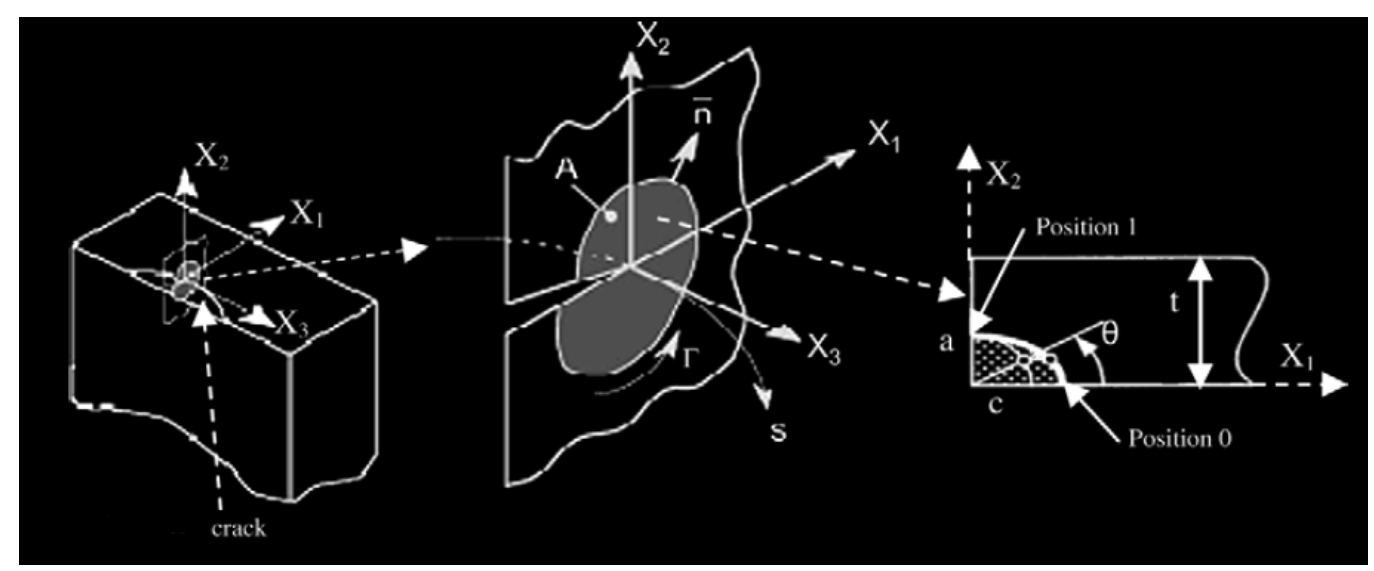

Figure14.J integral in three dimensions (3-D) [13]

The evolution of the J-integral in different contours in the normal plane to the crack tip, for both pre-cracked and notched pipe, is represented in figure 15. Results converge to saturation values from the third contour in the case of a cracked pipe and the fourth contour in the notched pipe. This convergence proves that a good meshing was adopted. 

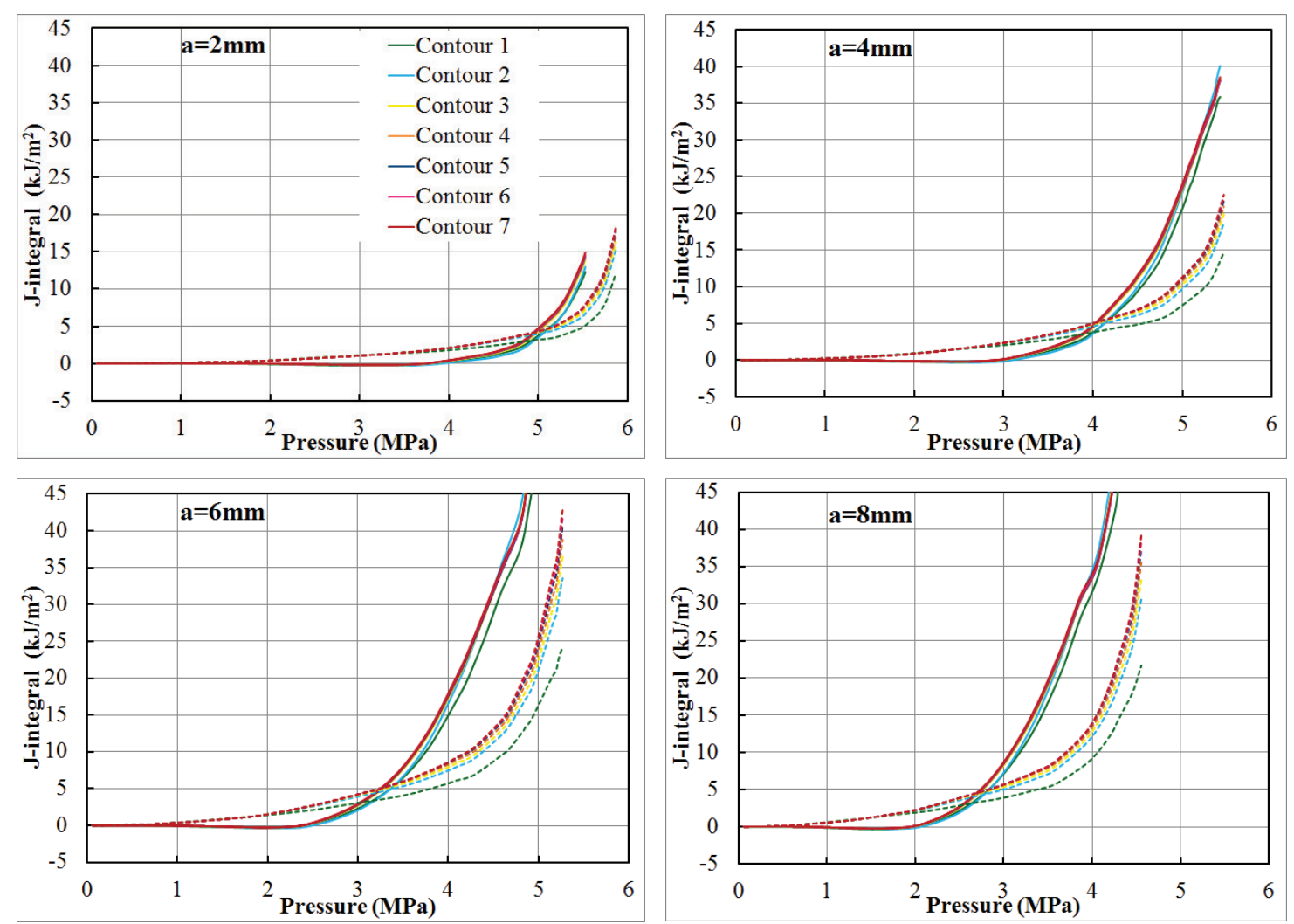

Figure15.Variation of the fracture toughness $J$ versus Pressure in different contour ( $a=$ Defect depth, continuous lines: Pre-cracked pipe, broken lines: Notched pipe)

In the case of a notched pipe, a plastic zone begins to appear and extends over a large area of the structure. In such a case the elastic-plastic stress at notch root increases to a maximum stress then decreases until reaching a certain distance referred to ( $X_{\text {eff }}=1.05 \mathrm{~mm}$ ) (Figure 16a).Therefore, at low pressure, the J-integral which is a parameter that describes the state of the crack growth is higher than in the case of pre-cracked pipe (Figure 15) where the plastic zone appears later and is still confined to the crack tip. So, the stress concentration is considerably higher in the case of pre-cracked pipe (Figure 16-b). This explains the strong rapid rise in J when the load reaches a level close to the critical value needed to propagate the crack. In the case of notched pipe, however this increase does exist but it this increases, although it exists, remains relatively slower (Figure 15). 


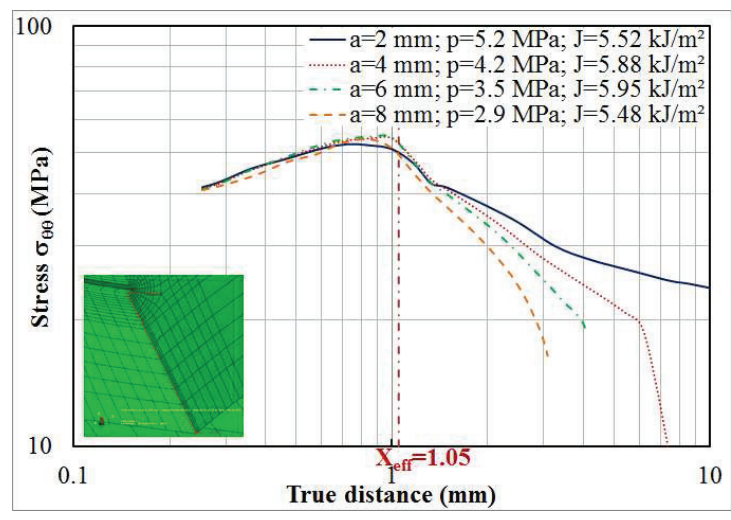

a) Notched pipe

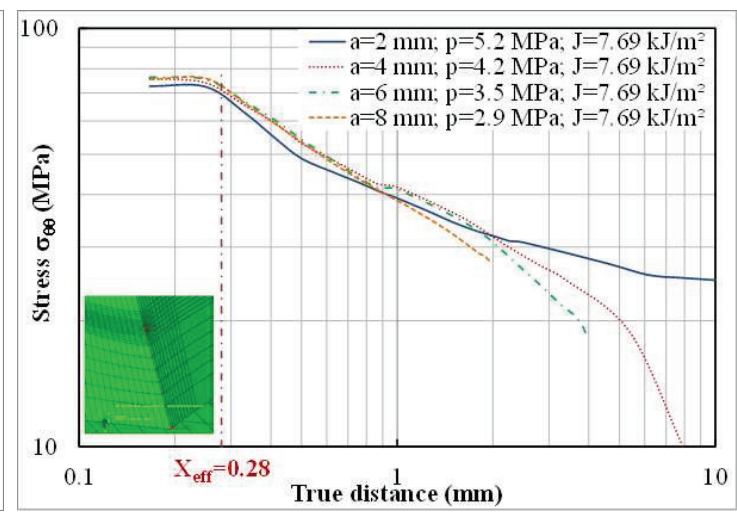

b) Pre-cracked pipe

Figure 16.Maximum principal stress $\left(\sigma_{\theta \theta}\right)$ distribution along the crack ligament

Now, it becomes possible to discuss and justify (as mentioned in sub-section 2.2) the choice of $J_{0.2}$ as a critical value of the J-integral. This can be achieved by plotting the opening stress , $\sigma_{\theta \theta}$, and the Von Mises stress, $\sigma_{\text {Mises }}$, distribution along the ligament in a pre-cracked pipe when the J-integral is equal to $6,7.69\left(\mathrm{~J}_{0.2}\right)$ and $14.1\left(\mathrm{~J}_{0.4}\right) \mathrm{KJ} / \mathrm{m}^{2}$ (see figure 17 and 18).

We note that a damaged region (plastic zone) appears when the J-integral found by ABAQUS is close to the value of $J_{0.2}$ measured experimentally. For $J=J_{0.4}$ (red curve), the damaged region is much more remarkable. So, it is more conservative to take $J_{0.2}$ as a J-integral critical value.
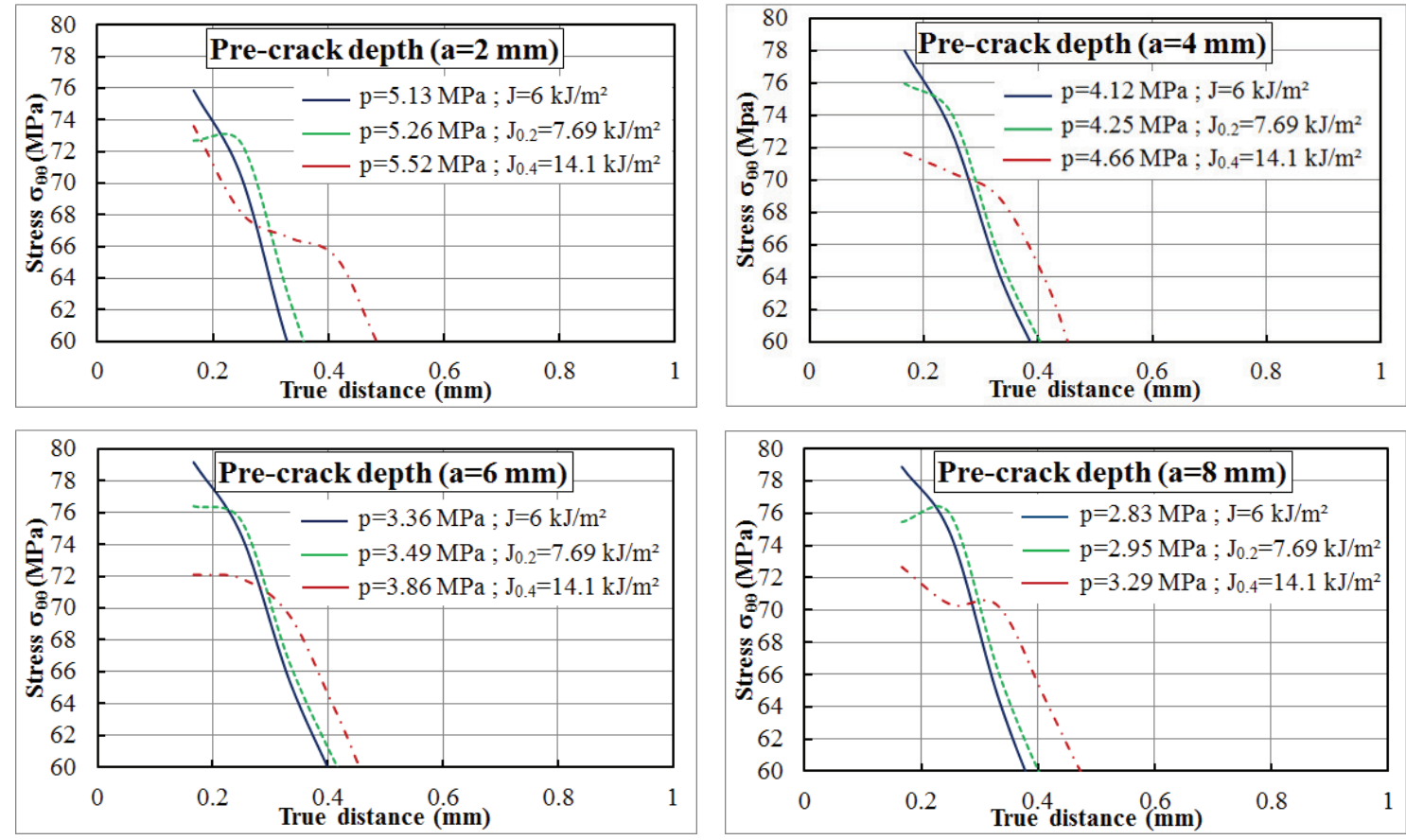

Figure 17.Maximum principal stress $\left(\sigma_{\theta \theta}\right)$ distribution along the crack ligament (in the vicinity of the crack tip) 

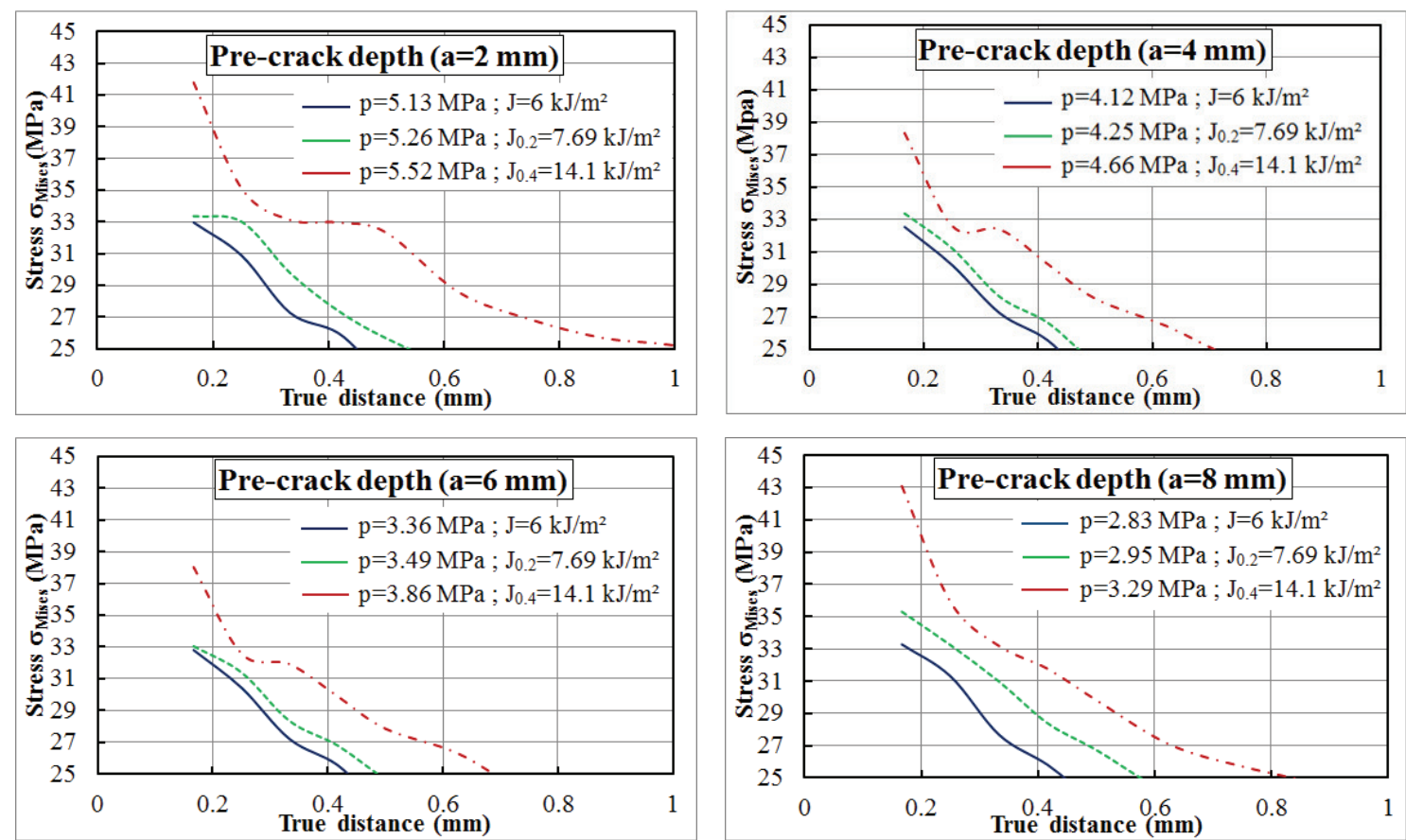

Figure 18.Von Mises stress ( $\sigma_{\text {Mises }}$ ) distribution along the crack ligament (in the vicinity of the crack tip)

The value of the critical fracture resistance $\left(\mathrm{J}_{\mathrm{IC}}=7.69 \mathrm{KJ} / \mathrm{m} 2\right)$ allows to determine the internal pressure which leads to the crack initiation. The values of this pressure are deduced from figure 15 and are presented on figure 19 as a function of the defect's depth.

For notched pipe these pressures are higher than pre-cracked pipe ones because they have a more important stress concentration in the vicinity of the crack tip (Figure 16-b). The interpolation curve of the points takes a parabolic shape. While the gap between the curves remains constant until a defect depth of $6 \mathrm{~mm}$ (half wall thickness) is reached while it increases when the defect is deeper than $6 \mathrm{~mm}$. This increase can be explained by the edge effects shown in figure 19. 


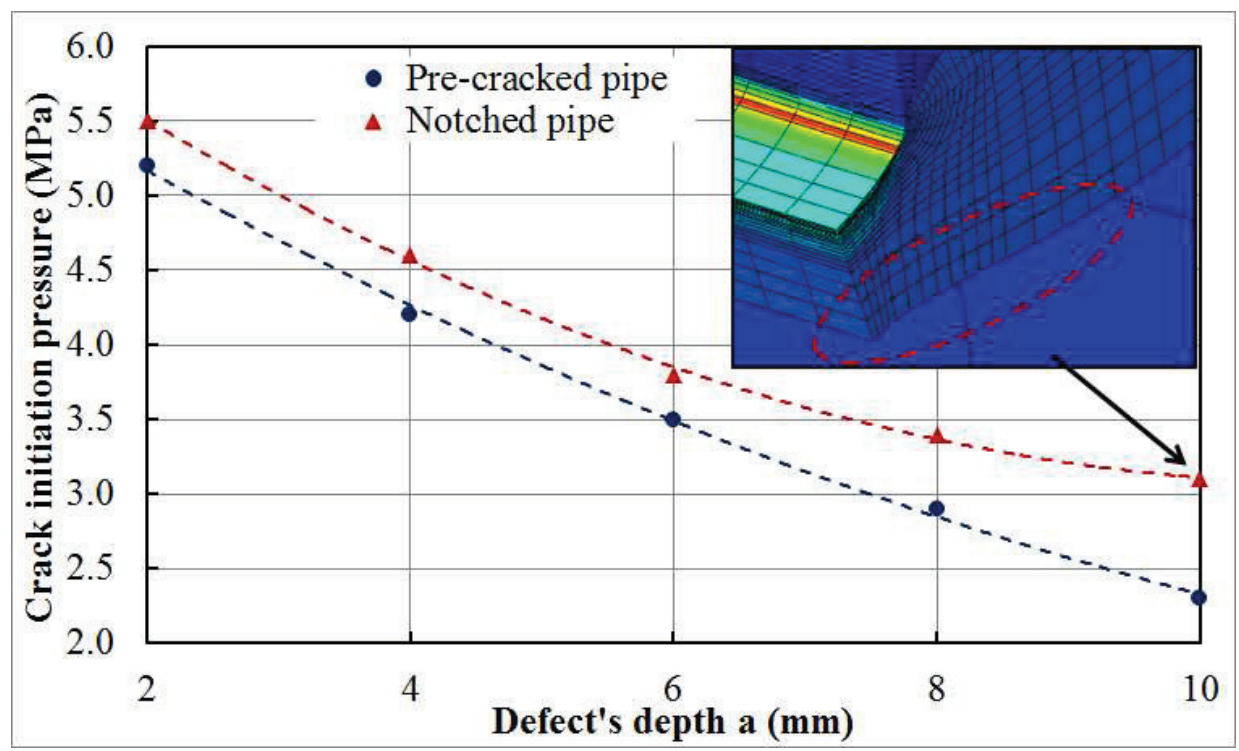

Figure 19.Crack initiation pressure vs defect depth

\section{Experimental and Numerical results analysis}

Both experimental and numerical Curves of the internal pressure as a function of water volume added to each specimen during burst tests are presented in figure 20 .

The numerical results agree well with the burst test results. The relative weak errors can be mainly caused by two factors. First, the HDPE is actually a viscoelastic-plastic material, whereas in the numerical model is described as an elastic-plastic which may result in an overestimation of the HDPE properties. Second, it can be caused by experimental errors such as measurement and leak.

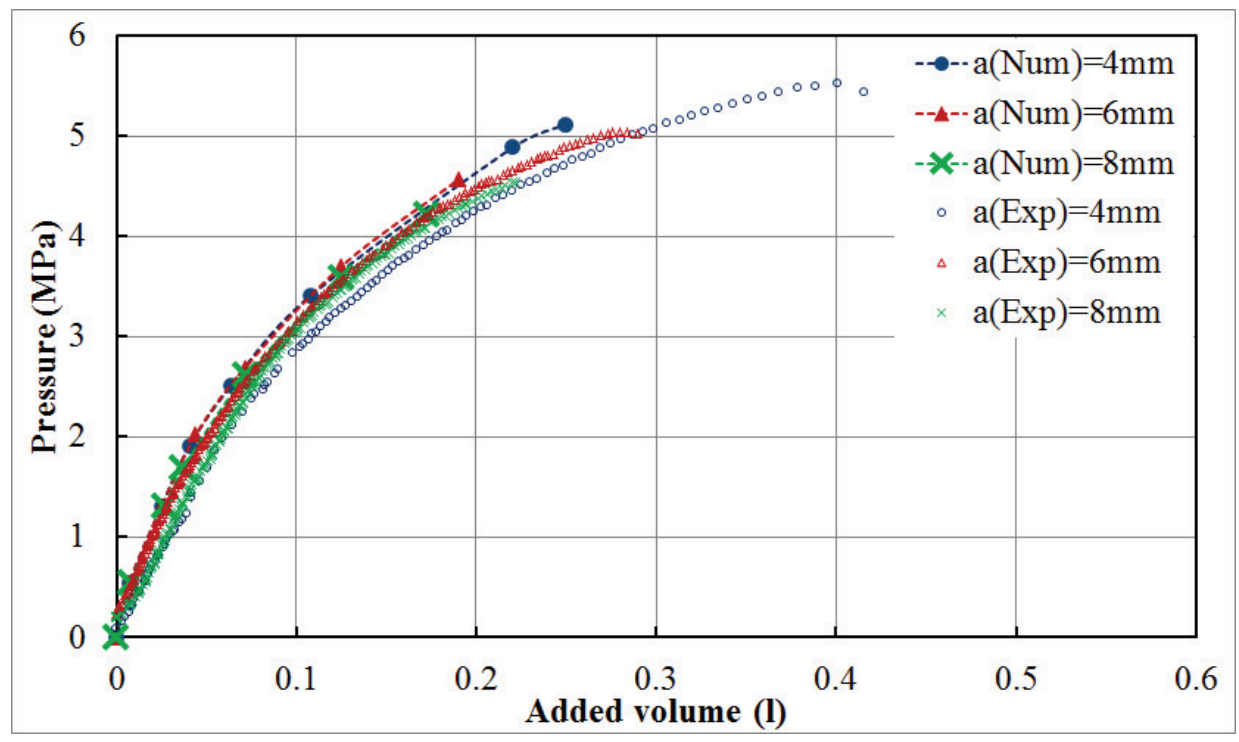

Figure 20.Pipe's internal pressure vs added water volume during the Burst test $(a=$ Notch depth) 
The burst pressure for each notch depth $(4 \mathrm{~mm}, 6 \mathrm{~mm}$, and $8 \mathrm{~mm})$ is deduced from the figure 20 and represented by green points on figure 21. This figure shows that the burst pressure decreases linearly with the notch depth. However, the decrease of the crack initiation pressure, numerically predicted, is parabolic.

This interpolating curve establishes the minimum pressure needed to initiate a crack. So the zone located under this curve is a safety zone. Beyond this curve, the damaged region expands in size over time and the crack propagates until pipe failure (figure 21).

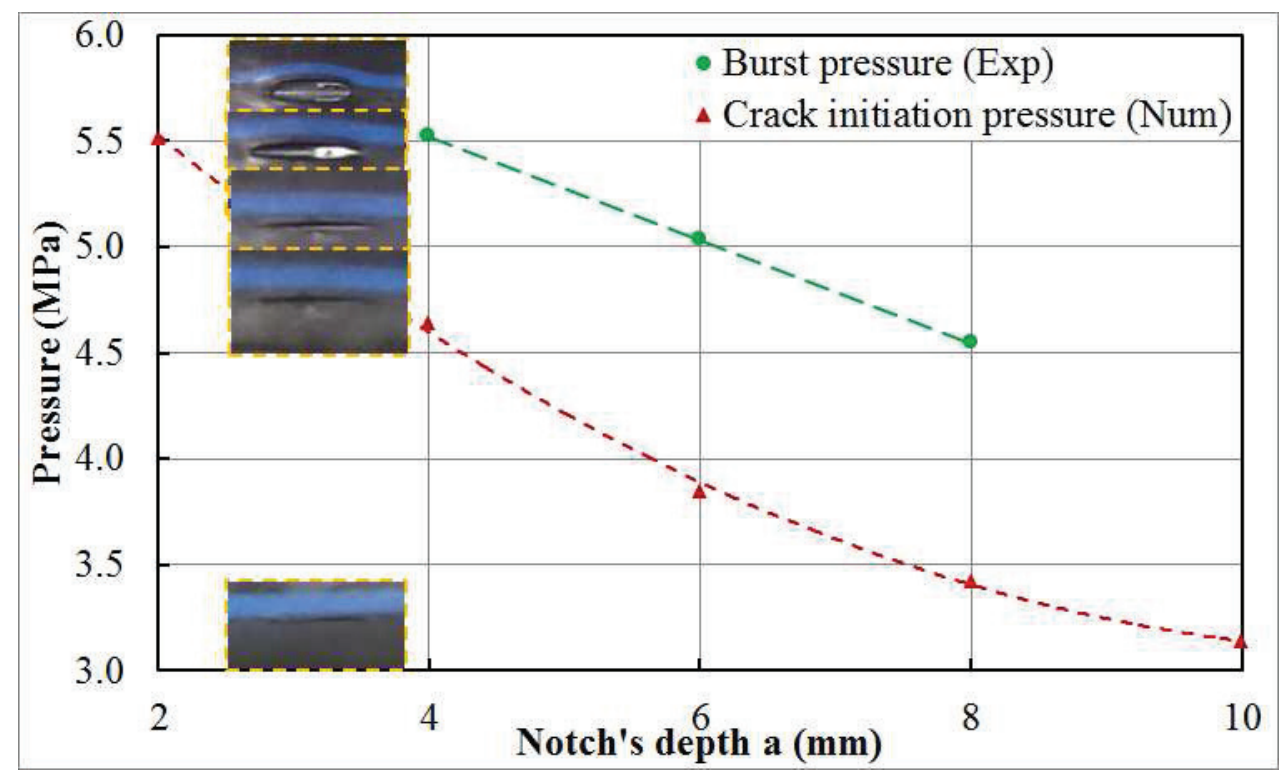

Figure 21.Pressure variation $v$ s notch's depth

\section{Conclusion}

PE100 cannot be treated by classical fracture mechanics. In this case the procedure is inappropriate and too much conservative. This kind of material induces viscoelastic-plastic failure and can be assessed by Elastic-Plastic Fracture Mechanics theory (EPFM) based on the J-integral concept. In this paper, an experimental study led to draw the J-R curve and deduce the critical value of the J-integral. Numerical simulations of longitudinally pre-cracked and notched pipes allow studying the evolution of the J-integral over a linear pressure loading (12 bar/min). These simulations allowed determining the crack initiation pressure for pre-cracked as well as notched pipes. In the two cases, it decreases parabolically with the defect's depth. There is a constant gap until a defect depth of $6 \mathrm{~mm}$ (half wall thickness) is reached. However it increases when the defect is deeper than $6 \mathrm{~mm}$. The numerical model was validated by the burst tests through comparing the pressure variation versus the volume of added water. 
The experimental results of defected pipes with defect depth between $4 \mathrm{~mm}$ and $8 \mathrm{~mm}$ show that the burst pressure decreases linearly with the notch depth. However to conclude about the general shape of burst pressure as function of defect's depth more experimental tests will be conducted in the upcoming studies. Results in this paper show that the J-integral can be used as a criterion to evaluate the severity of a small width notch.

\section{References}

[1] World Plastic Pipe Industry Study with Forecasts for 2017 \& 2022, April 2013.

[2] ANSI/AWWA C906 American National Standard for Polyethylene (PE) Pressure Pipe and Fittings, 4 In.Through 63 In., For Water Distribution, American Water Works Association, Denver, Colorado (1999).

[3] Ainsworth R.A. The assessment of defects in structures of strain hardening materials. Engineering Fracture Mechanics 1984; 19:633-42.

[4] Miller A.G. Review of limit loads of structures containing defects. International Journal of Pressure Vessels and Piping 1988; 32:197-327.

[5] Zahoor A. Ductile fracture handbook 1991; EPRI/NP-6301.

[6] Rahman S. Net-section-collapse analysis of circumferentially cracked cylinders - part II: idealized cracks and closed-form solutions. Engineering Fracture Mechanics1998; 61:21330.

[7] Bouaziz M.A, Guidara M.A, Schmitt C, Hadj-Taïeb E, Azari Z. Water hammer effects on a gray cast iron water network after adding pumps, Engineering Failure Analysis 2014; 44: $1-16$.

[8] Moustbachir H, Azari Z, Hariri S, Dmytrakh I. Experimental and numerical study of stress- strain state of pressurised cylindrical shells with external defects, Engineering Failure Analysis 2010; 17: 506-514.

[9] Kim Y.J, Shim D.J, Nikbin K, Kim Y.J, Hwang S.S, Kim J.S. Finite element based plastic limit loads for cylinders with part-through surface cracks under combined loading. International Journal of Pressure Vessels and Piping2003; 80:527-40.

[10] Kim Y.J, Shim D.J, Nikbin K, Kim Y.J, Hwang S.S, Kim J.S. Elastic-plastic fracture mechanics assessment of test data circumferential cracked pipe.Engineering Fracture Mechanics 2004; 71:173-91

[11] Allouti M, Schmitt C, Pluvinage G, Gilgert J,Hariri S. Study of the influence of dent depth on the critical pressure of pipeline. Engineering Failure Analysis 2012; 21: 40-51. 
[12] Allouti M, Schmitt C, Pluvinage G. Assessment of a gouge and dent defect in a pipeline by a combined criterion. Engineering Failure Analysis 2014; 36: 1-13.

[13] Benhamena A, Bouiadjra B, Amrouche A, Mesmacque G, Benseddiq N,Benguediab M. Three finite element analysis of semi-elliptical crack in high density poly-ethylene pipe subjected to internal pressure. Materials and Design 2010; 31: 3038-3043

[14] Benhamena A, Aminallah L, Bouiadjra B, Benguediab M, Amrouche A, Benseddiq N $\mathrm{J}$ integral solution for semi-elliptical surface crack in high density poly-ethylene pipe under bending. Materials and Design 2011; 32: 2561-2569.

[15] Wu J., Mai Y.W. The essential fracture work concept for toughness measurement of ductile polymers. Polymer Engineering and Science 1996; 36: 2275-2288.

[16] Kwon H.J, Jar P.Y.B. New energy partitioning approach to the measurement of planestrain fracture toughness of high-density polyethylene based on the concept of essential work of fracture. Engineering Fracture Mechanics 2007; 74: 2471-2480.

[17] Rice J.R. A Path Independent Integral and the Approximate Analysis of Strain Concentration by Notches and Cracks. Journal of Applied Mechanics 1968; 35: 379-386.

[18] Ferhoum R. Experimental study and numerical modeling of the mechanical behavior of HDPE in virgin form and after thermal aging. Doctoral thesis, Université MOULOUD MAMMERI de Tizi-Ouzou, Juin 2012.

[19] G'Sell C, Hiver J.M, Dahoun A. Experimental characterization of deformation damage in solid polymers under tension, and its interrelation with necking. International Journal of Solids and Structures 2002; 39: 3857-3872.

[20] ASTM D 6068 Standard Test Method for Determining J-R Curves of Plastic Materials.

[21] ISO 13586:2000 Plastics - Determination of fracture toughness (GIC and KIC) - linear elastic fracture mechanics (LEFM) approach

[22] Smith E. The use of eta factors to describe the J integral: the ASTM 1152 standard for the compact tension specimen. Engineering Fracture Mechanics 1992; 41: 241-246.

[23] Garcia Brosa V, Bernal C, Frontini P. Calibration of fracture mechanics parameters and J-R curve determination in polyethylene side-grooved arc shaped specimens. Engineering Fracture Mechanics 1999; $62: 231-248$.

[24] Clarke G.A, Landes J.D. Evaluation of the J-integral for the compact specimen. J Test Evaluat 1979;7: 264-9.

[25] ASTM E813-81. Standard test method for JIc, a measure of fracture toughness. American Society for Testing and Materials; 1982. 
[26] Huang D.D. Applying fracture mechanics to materialsselection. Plastics Engineering, June 1996, p. 37-39, 5 fig., 6 réf. bibl., the Society of Plastics Engineers.

[27] Williams J.G. Fracture mechanics of polymers. Ellis Horwood Ltd. Publ., 1987,302 p.

[28] Tancrez J.P,Pabiot J,Rietsch F.Damage and fracture mechanisms in thermoplasticmatrix composites in relation to processing and structural parameters. Composites Science and Technology 1996; 56: 725-731.

[29] Saleemi A.S, Nairn J.A. The Plane-Strain Essential Work of Fracture as a Measure of the Fracture Toughness of Ductile Polymers.PolymEngngSci 1990; 30(4):211.

[30] Brostow W, Fleissner M, Müller W. Slow crack propagation in polyethylene: determination and prediction 1999; Polymer; 3:419-25.

[31] Favier V, Giroud T, Strijko E, Hiver J.M, G'Sell C, Hellinckx S, Goldberg A. Slow crack propagation in polyethylene under fatigue at controlled stress intensity 2002;Polymer; 43:1375-82. 